\title{
Managing Quality Education - Identifying the Learning Needs of the Individual, Then Satisfying Them
}

\author{
Don Passey \\ Department of Educational Research, Lancaster University, UK \\ d.passey@lancaster.ac.uk
}

\begin{abstract}
Do teachers have access yet to the forms of data that will allow them to meet the needs of different learners? School head teachers and managers, when seeking to manage quality education, are challenged by the dilemmas of balancing quality of provision through classroom interactions with quality of provision that meets the needs of the individual learner. A number of processes and technologies are now available that support schools in managing those balances: availability of data; access to different forms of data; and technologies that support areas of learning and different learning approaches. Although there is continued development of systems to support schools in each of these areas, this paper will argue that there is need to consider further development in all of these areas, and to link up critical elements and features more. This paper will look at, in a United Kingdom (UK) context: the forms of data normally accessible to schools; an example of the ways that some forms of technology are supporting the learning needs of the individual; and an indication of the limitations for consequential quality management arising from lack of 'learning-to-data-to-learning' links.
\end{abstract}

Keywords: Managing quality education, individual learning needs, data management systems, formative assessment, social and emotional aspects of learning.

\section{Introduction}

A teacher recently shared a concern with me: she said that there are some students in her classes who really do not understand algebra, and she does not know why. To help them, she wants to know why they do not understand algebra, and what learning approaches or pedagogic practices she might use to help them, rather than being told from test and data records that they do not understand algebra. In essence, the issues at the heart of this concern are those considered in this paper.

School head teachers and managers seek to manage quality education in a range of ways; they seek to manage the quality of school environments for learning, of teacher interactions to support learning, and of interactions that support the needs and interests of the individual learner. It is clear that school head teachers and managers, as well as teachers themselves, when seeking to manage quality education through these domains, are challenged by the needs to balance quality of provision offered through classroom interactions with quality of provision that meets the needs of the 
individual learner. In the context of the United Kingdom (UK), an increasing emphasis has been placed on the importance of engaging in a personalisation of learning, discussed in the Report of the Teaching and Learning in 2020 Review Group (2006). This influential report emphasised the need to consider ways that schools and learning might be transformed, as well as a review of the integration of assessment and data management to support those goals. It stressed that personalising learning should be learner-centred, knowledge-centred, and assessment-centred; some of the characteristics associated with personalising learning that were stated in the report included 'close attention ... paid to learners' knowledge, skills, understanding and attitudes', learning 'connected to what they already know (including from outside the classroom)', teaching that engages pupil 'interest in learning, ... identifies, explores and corrects misconceptions', learners being active so that they 'create their own hypotheses, ask their own questions, coach one another, set goals for themselves, monitor their progress, ... knowing that mistakes and 'being stuck' are part of learning', with assessment being both formative and summative, supporting learning, and identifying next steps.

A number of facilities and technologies to help schools manage the balances and approaches concerned with personalising learning are becoming increasingly available. Data relating to individual learners is increasingly accessible online, through systems that provide access over the period of their school careers, there is increasing access to different forms of data (so that statutory test and examination data can be supplemented by data relating to attitudes, behaviour, and learning access outside school), and how technologies can support areas of learning, pedagogies and different learning approaches are being detailed and understood to greater extents.

In this paper I will consider a current 'data dilemma'. I will explore the current forms of data that are accessible to teachers in schools in the UK, and the (sometimes limited) ways that those data can be accessed and associated with individual learner characteristics. I will indicate evidence from research reports that shows that technologies are supporting some learners with specific social or emotional characteristics, but that the data accessible to a teacher neither allows attainment or achievement to be easily viewed through those learner groupings, nor allows access to information and advice to offer alternative ways to support a personalisation of learning for those learner groups.

\section{Data Accessible to Schools}

Schools in the UK have access to a wide range of data, and in many cases schools record and use data that is additional to statutory test and examination results. Data normally accessible to schools includes background results (prior national attainment or non-statutory test results in subjects at the end of a period of schooling referred to as a Key Stage), estimated likely outcomes (estimated future results based on previous performance, statistically produced and validated), targets (future targets generated by statistical engines, or by pupils, teachers or school leaders, so that they can be used as an aspirational focus), teacher assessments (subject attainment results entered by teachers to show achievement at specific points in time, and in some cases also records made regularly by teachers about homework completion, attendance, effort in 
class, or behaviour in school), added value measures (indicating the value added at the end of a particular period of time, usually at the end of a Key Stage, generated and presented in the form of either raw score added value, or contextual added value moderated according to individual or school context, or within school variation value moderated according to previous school performance or school subject comparison). The forms of data listed here are widely used, but generally offer ideas about subject content or attainment, rather than ideas of pedagogic practice.

Some schools select to gather other data, including data from specific tests that provide measures other than subject attainment outcomes. For example, the GL Assessment (2009) Cognitive Abilities Tests (CATs) provide perspectives about learning potential; these are not subject focused (they indicate standardised scores for quantitative, qualitative and non-quantitative reasoning). Some online resource facilities monitor and report individual learner access levels outside as well as inside school, with access rates and outcome measures reported back to schools (SamLearning, n.d., for example). Some schools record details concerned with social and emotional attitudes to learning (SEAL), discussed in government education department guidance (DfES, 2005), and in this context, while many schools record details of attendance and behaviour, fewer maintain specific records of selfawareness, the managing of feelings, motivation, empathy, and social skills. Some of these social and emotional features are regularly tested in some schools using tests that measure attitudes of learners to aspects of readiness for and confidence in learning, feelings about school, perceived learning capability, self-regard, attitudes to teachers, to work, and to attendance, using a system such as the Pupil Attitude to Self and School (P.A.S.S.), for example (W3 Insights, n.d.). For those schools that gather these records, the data tend to offer insights into the contexts of learner engagement, however, rather than giving ideas directly about content or pedagogic preference (except in the case of CATs).

\section{Access to Data in Schools}

Schools can access these data in a number of ways, through a number of different access points, many through online portals, and some in hardcopy form (these are discussed in more depth in Passey, 2009). The tracking of data through the individual child, however, a need that teachers have desired for many years and highlighted by work of the author in 2002 with the government department in England, and summarised in a later paper (Passey, 2007), is now beginning to become more easily available to local authorities (LAs) and schools through the work and development of the Fischer Family Trust with its Student Explorer system (2009), and through facilities offered in management information systems.

While data that is linked to the individual child enables LAs and schools to look at background data and estimated likely outcomes (and often attendance data), links to other forms of data such as attitude are not currently so easily accessible, for either comparative or selection purposes. However, data that allows filtering to highlight similarities or differences with specific groups of pupils are becoming increasingly accessible. Filtering factors such as ethnicity, gender, special educational needs, additional language needs, and socio-economic indicators are being built into systems 
such as Student Explorer. Whilst uses of these forms of group filter data have been in place for some time (see DfES, 2002, for example), there has been increased interest in use of these data to explore impacts of background circumstances as well as specifically targeted interventions. A key question still remains however - if certain mechanisms or interventions are recognised to support personalised learning in certain ways, are appropriate and relevant data routinely collected and made available to teachers and managers so that they can set up and support quality interventions (where quality can be judged by shifts in attainment or achievement at individual as well as at group level)? In the next section, an example will show that systems in place do not yet allow for this need.

\section{How Technologies Are Supporting Some Individual Learners}

Many learning support interventions have been introduced into schools in the UK over the past 20 years. A range of these have involved and continue to involve technologies. Evidence presented in this section will indicate that a certain range of technologies and associated interventions can support a certain group of learners (evidenced by reports from learners themselves and from teachers).

Government education policy in England, initially defined in a report by the government education department (DfES, 2005), and later described within an implementation plan from the government agency for e-strategy (Becta, 2007), highlighted the need for schools and LAs to focus on effective implementation of certain specific learning and teaching practices. These practices included the personalisation of learning, the harnessing of technologies to enhance learning opportunity and effectiveness, the eliciting and integration of student voice, and the widening of home access and support. To this end, schools were (and still are) encouraged to implement e-learning practices, including approaches that use learning platforms, virtual learning environments (VLEs) and e-mentoring systems. A range of VLEs is accessible to schools across the UK. In this paper, learning outcomes from uses of two VLEs will be considered. The first, Virtual Workspace, was introduced into two LAs for use by all secondary schools and their learners aged 14 to 19 years. Findings from this implementation (Passey, 2007b) are included here, and are supplemented with findings from a second study that explored aspects of the implementation of a second VLE, LP+ (Learning Possibilities, 2009), introduced into one of these two LAs for use initially by all primary schools and all learners aged 4 to 11 years, and extending into use into secondary schools at a slightly later stage.

The two VLEs both provided similar ranges of facilities, although different facilities were accessible for different users (teachers, school managers, LA consultants, pupils, parents and governors). However, there were some differences between the two VLEs. In the case of Virtual Workspace, facilities included: a range of communication channels, including messaging, discussion forums and chat rooms; online assignment management and storage of work and interest materials; online communities, offering collaboration between learners and teachers across schools; a mentoring service, involving live mentoring between $8 \mathrm{am}$ and $8 \mathrm{pm}$ on weekdays; a bank of interactive learning materials supporting the curriculum for 14 to 19 year old learners; an incentive or reward scheme for learners; and a continuing professional 
development (CPD) programme for teachers and support staff, run by the commercial providers. In the case of $\mathrm{LP}+$, facilities included the integration of: messages in the forms of notices from head teachers and in the form of news items; document handling and storage, for weekly as well as longer-term plans, organised by year groups, and able to accept online feedback from school managers; a calendar, and reporting of events, with online meeting spaces; an area to report technical faults (picked up locally by LA consultants) and access to support and training resources; discussion areas; surveys; subject areas within each school site; facilities for inclusion of school television or radio broadcasts; resources to support specific aspects of subject learning; a CPD programme for teachers and support staff run by LA consultants with training from $\mathrm{LP}+$; networking tools in the forms of blogs and wikis; online spaces to share profiles and successes, task setting and tracking tools; assignment management tools; content repositories; an online text editor; paint and draw applications; an early years media player; search tools; and mobile compatibility and synchronisation.

To date, much of the evidence of benefit and outcomes arising from VLEs has been identified from uses within the higher education (HE) and further education (FE) sectors. As Condie et al. (2007) stated: "Specific benefits observed in the HE/FE sector ... included improved motivation and engagement, flexibility of access, learning gains in ICT, in writing, understanding and presentation, enhanced communication and interaction, plus the adoption of new approaches to learning". Since 2005, research findings have increasingly pointed to learning benefits arising where learning environments and VLEs have been adopted in some schools. Condie et al. (2007) stated that Becta found that: “... learners benefited from them in that they could extend their learning experiences beyond the confines of the classroom, submit and track electronic activities for assessment and manage aspects of their personalised learning".

The studies of the two VLEs reported in this paper gathered evidence that allowed perceptions and outcomes of implementation and uses to be viewed from different perspectives. Evidence was gathered in the first case (Virtual Workspace) through visits to 10 schools (selected on the basis of their different levels of learner and teacher use and different approaches to implementation of the system). Interviews with head teachers, senior managers, information and technology (ICT) co-ordinators, teachers, and learners gathered views about practices involved from management, teacher and learner perspectives, the recognition of positive and negative aspects arising, unique features identified, the roles of mentors, how uses matched approaches to learning, the recognition of pedagogies to complement online and personalised learning, aspects of change management that were considered to be of importance, and evidence of learning outcomes arising (in total, from 11 head teachers and senior managers, 7 ICT co-ordinators, 23 teachers and a teaching assistant, and 61 learners). Subsequently, further evidence was gathered through discussion and feedback with key personnel, including mentors in the management company, discussions with key project personnel through face-to-face, email and telephone means (16 in total), and completion of online questionnaires by a wide sample of learners across all schools (1,486 learners in total). Web-based materials, project documents and statistical evidence were also examined as a part of the study. Evidence was gathered in the second case $(\mathrm{LP}+$, where implementation was more recent), from LA consultants 
(who completed a grid of features, providing implementation details at a school level for all 63 schools initially involved), from 5 key personnel in the LA (through discussion), and from key personnel in 22 schools (who identified key features for the implementation through discussions).

From all forms of evidence gathered it was clear that not all learners had necessarily benefited to the same extents (or in the same ways). When learners used the Virtual Workspace system, the evidence suggested that those benefiting were often reported to be gaining through the nature and focus of social interaction, rather than gaining through forms of direct information transfer. In terms of those who were reported to benefit through these forms of social learning provision, it was not necessarily those who talked most in classrooms. These learners were likely to be those within classrooms that teachers would regard as being 'shy' or 'quiet' (perhaps not wishing to make their thoughts public, or not wanting to be seen by others to be actively participating). By comparing the responses of 'shy' boys (179 in total) with self-reported 'non-shy' boys (354 in total), the percentage of responses from 'shy' boys was higher in their reports about being more involved in learning than might have been the case otherwise ( $24 \%$ difference, $\left.\chi^{2}=34.17, \mathrm{p}<0.0001\right)$, discussion of work outside the classroom $\left(21 \%\right.$ difference, $\left.\chi^{2}=21.19, \mathrm{p}<0.0001\right)$, allowing ideas to be expressed when this might not happen in class $\left(20 \%\right.$ difference, $\chi^{2}=18.31$, $\mathrm{p}<0.0001)$, helping to understand teachers more $\left(13 \%\right.$ difference, $\chi^{2}=12.11$, $\mathrm{p}<0.0005)$, helping with coursework or assignments $\left(13 \%\right.$ difference, $\chi^{2}=8.68$, $\mathrm{p}<0.0032)$, mentors helping personally ( $13 \%$ difference, $\left.\chi^{2}=10.43, \mathrm{p}<0.0012\right)$, and wanting to see more use of the system $\left(12 \%\right.$ difference, $\left.\chi^{2}=9.02, \mathrm{p}<0.0027\right)$. By comparing the responses of 'shy' girls (412 in total) with 'non-shy' girls (541 in total), the percentage of responses from 'shy' girls was higher in their reports about allowing ideas to be expressed when this might not happen in class ( $16 \%$ difference, $\chi^{2}=23.58, \mathrm{p}<0.0001$ ), and being more involved in learning than might have been the case otherwise $\left(14 \%\right.$ difference, $\left.\chi^{2}=25.01, \mathrm{p}<0.0001\right)$. In all the instances highlighted, statistically significant differences were shown between the 'shy' group and the 'non-shy'group of learners. It is clear from these data that the 'communities' area of the VLE was felt by more 'shy' or 'quiet' learners through their questionnaire responses (and this was supported by individual discussions with learners and by teacher responses) to support to a greater extent an engagement with learning.

Evidence from teachers using the other VLE system supported these conclusions, and offered further evidence about the nature of interactions that were ocurring. In one of the schools involved in using the $L P+$ system, the teacher set up a discussion about a poem, The Highwayman and Bess. The activity related to a unit of work that had been covered 3 weeks beforehand in class, so the discussion replicated some of this work. The lead teacher found that the online discussion that learners could contribute to at home as well as at school engaged pupils, and that it continued for many months (at least 7 months of discussion were recorded). On occasions the time intervals between pupil responses were short; pupils were involved as they would be in a conversation. From the contributions to the discussion, the lead teacher could see individual pupil opinions and their interests, and these she could access in textual 
form (which she found to be particularly valuable, since previously she had found that an assessment of verbal opinions could lead to rather general indicators being identified only). She found that a textual discussion was giving her more detailed evidence, and she could go back to it whenever she wanted to gather further detail to inform her assessments. She found that comments came from some pupils who might not have been expected to comment; one deaf child used the facility a lot, and his confidence in responding was supported by opportunities to discuss his ideas with someone at home before he wrote his responses. The teacher found that the online discussions were particularly valuable, as pupils could: write an opinion; handle different opinions more easily; reason in a more measured way even when they were challenged; be less aggressive than they might be in face-to-face discussions (which would tend to be taken more personally); respond more easily to written (rather than verbal) material; accept written comments more objectively and less emotionally; take time in reading, thinking, and then responding; take more time to think about a reference to another idea or another text; and respond in their own way, rather than backing down as they might in class. The online discussion was reported to engage the pupils; it appeared to gain their attention so that they remembered it and the poem as a consequence; the teacher found that pupils could still quote lines from the poem some 7 months after encountering the poem in class. Evidence from another school using the same system indicated that online discussion was engaging learners in writing and completing homework, those who were in class situations 'shy' with regard to both writing and communication (and the teacher suggested some 6 learners within a class of 30 would have had these characteristics).

In all of the cases above, teachers are noticing impacts of a technology-based facility on specific groups of pupils. However, there was no indication that prior recorded data was being used to identify these pupils, or that the findings of these teachers were being used to link potentially useful learning opportunities for the benefits of others with similar characteristics or for teachers with learners of similar characteristics in their classes. The personalisation of learning for these individuals happened through fortunate opportunity rather than through guided advice, planning or design. The facilities did not enable these opportunities to be highlighted for other teachers and other learners who might benefit from them. Yet it was clear that outcomes for these learners when using these facilities was important to them and to the teachers; having data facilities to support the 'learning-to-data-to-learning' link could be important for other learners where these experiences have not been 'tried and tested'. This is an example of a pedagogic practice being explored that, if highlighted in some way for other teachers and classes, might well support a wider number of learners.

\section{Conclusions}

The previous section identifies a specific example, but highlights a key issue. 'Shy' or 'quiet' learners are increasingly being recognised by teachers across a range of age groups as being learners who should be supported more. Evidence from practice shows that some of these learners can be supported by e-mentoring and online support 
systems, potentially providing schools and teachers with useful approaches to enhance learning. But how can a widening of experiences be managed within a school or classroom environment? Does data allow school managers and teachers to consider how to support these individual pupils best?

Does the standard data provision help? Prior national attainment or non-statutory test results, estimated future results based on previous performance, subject attainment targets, teacher subject attainment assessments, and added value indicators are all measures focused on subject content, rather than pedagogic or learning process (although some of these data might allow teachers to pick up on low levels of pupil writing, pointing to or suggesting support through appropriate uses of a VLE). Indicators of attendance, effort, or behaviour in school might highlight when contextual issues are arising, but do not offer any direct indication of potential actions in terms of pedagogic or learning process (although indicators of low homework completion might suggest to a teacher that this issue could be supported through appropriate uses of a VLE).

Does SEAL data help? Attendance and behaviour records are likely to offer indicators of the time periods when disengagement issues might be arising, while specific records about self-awareness, the managing of feelings, motivation, empathy, and social skills could provide indicators that could point towards the potential for certain pedagogic or learning processes. However, teachers might well need to be offered specific ideas of pedagogic or learning processes that they might use when indicators highlight a need for intervention or support. A link between data indicators and pedagogic alternatives (which might be called 'data-driven pedagogic intelligence') can be made by those who are already aware of what the indicators might tell them, what processes might be suggested as alternatives, and which processes have worked for some learners in those categories on previous occasions. This form of 'learning-to-data-to-learning' link is supported by some data systems; the GL Assessment CATs data system offers measures of qualitiative, quantitative, and non-quantitative reasoning, and pedagogic and learning processes are suggested through accompanying materials.

Data from P.A.S.S. could also provide useful indicators for teachers, but the links between these indicators and pedagogic and learning alternatives are not provided through the current form of results as they are presented. Indeed, a research practitioner has recently undertaken a study to explore whether there is any correlational link between P.A.S.S. results and a lowering of results below those estimated from standard attainment tests in core subjects (English, mathematics and science). To undertake this work, the research practitioner had to manipulate the two sets of data to gain correlation results, had to interview learners to detail instances to greater extents, but then still needed to consider what pedagogic or learning alternatives might be available to her colleagues to address the issues.

So what is needed? The emphasis on personalisation of learning is clearly laudible; placing a learning provision that is learner-centred, knowledge-centred and assessment-centred offers potentially enhanced individual commitment, focus and ownership. However, managing quality educational experiences in this context, where data management can support a personalisation of learning (meeting the needs of individuals as well as specific groups) requires: the identification of learning and 
pedagogic practices that support specifically identified groups of learners (and in the current context this needs to be the first, rather than the last, step); an identification of those learner features that indicate which learners might be within these groups; a means to capture shifts in levels of these features and to make these shifts known to managers and teachers; and a subsequent provision that highlights for managers and teachers possible pedagogic and learning alternatives that might be adopted at times when these shifts emerge, perhaps through links to vignettes of practice, such as those in guidance documents or in video format (including teachers.tv, n.d.). School managers are increasingly using data management systems to help them manage some quality educational experiences, but using 'learning-to-data-to-learning' links (data highlighting those who might benefit from pedagogic and learning processes), are only now beginning to be created. There is clearly wide potential to develop resources in this area, to support desirable transformational development.

\section{Acknowledgements}

The author would like to thank Wolverhampton and Worcestershire LAs, Virtual Workspace, and LP+ for their support of key elements of research reported here.

\section{References}

Becta: Harnessing Technology Delivery Plan. Becta, Coventry (2007)

Condie, R., Munro, B., Seagraves, L., Kenesson, S.: The impact of ICT in schools: a landscape review. Becta, Coventry (2007)

DfES Primary National Strategy: Excellence and enjoyment: social and emotional aspects of learning - Guidance. DfES, Nottingham (2005)

DfES: Harnessing technology: Transforming learning and children's services. DfES, Norwich (2005)

DfES: Releasing Potential, Raising Attainment: Managing Data in Secondary Schools. DfES, London (2002), http://www.standards.dfes.gov.uk/ts/docs/RPRA.pdf (accessed December 11, 2009)

Fischer Family Trust. FFT Live Student Explorer. Fischer Family Trust, Cowbridge (2009), http://www.teachernet.gov.uk/_doc/14371/

Student_Explorer_V1_Notes.doc (accessed December 11, 2009)

GL Assessment: CAT - Cognitive Abilities Test. GL Assessment, London (2009),

http: //shop.gl-assessment.co.uk/home.php?cat=310

(accessed December 11, 2009)

Learning Possibilities. LP+. Learning Possibilities, Borehamwood (2009), http: / / www. learningpossibilities.net/ (accessed December 11, 2009)

Passey, D.: First no choice, then some choice, and finally overload: A reasonable data management evolution? In: Tatnall, A., Visscher, A., Finegan, A., O’Mahoney, C. (eds.) Evolution of Information Technology in Educational Management. Springer, New York (2009)

Passey, D.: Technology enhancing learning: Limited data handling facilities limit educational management potential. In: Tatnall, A., Okamoto, T., Visscher, A. (eds.) Knowledge Management for Educational Innovation. Springer, New York (2007) 
Passey, D.: Virtual Workspace: An Independent Evaluative Review. Wolverhampton: Wolverhampton City Council and Worcestershire County Council, Wolverhampton (2007b) Report of the Teaching and Learning in 2020 Review Group: 2020 Vision. DfES, London (2006)

SamLearning.com: SamLearning.com online learning. SamLearning, London (n.d.), http: / / www . samlearning. com/ (accessed July 13, 2007)

Teachers.tv. Teachers.tv, no place specified (n.d.), http: / /www. teachers.tv/ (accessed December 11, 2009)

W3 Insights: The P.A.S.S. Audit Process. W3 Insights, no place specified (n.d.), http://www.w3insights.pass-survey.com/audit_process.htm (accessed December 11, 2009) 